\title{
Prediction of the Spinning Triangle Height in Ring Frame Using Artificial Neural Networks
}

\author{
M Murugesan $^{1}$, T Senthilkumar ${ }^{2}$ and R C Nayar ${ }^{1}$ \\ ${ }^{\text {I}}$ (Department of Textile Technology, A C Tech, Anna University, Chennai, Tamil Nadu, India) \\ ${ }^{2}$ (Mechanical Processing Division, ICAR-Central Institute for Research on Cotton Technology, Mumbai, India)
}

\begin{abstract}
In this study, a group of polyester multi-filament yarns were fed to the ring frame at the backside of the front roller. A particular width was set for the filament group at backside of the front roller and the left out filament was twisted by ring-spindle. The height of the spinning triangle was measured for various parameters, such as the width of the filament strand spread, the number of filaments in the group, and the twist inserted by the traveller in the yarn. A CCD image camera was used to take the image of the spinning triangle and its height was measured from the image. The spinning triangle height was also predicted with the help of regression equation and artificial neural networks (ANN) and the values were compared with the experimental values. This study clearly shows that the triangle height is directly proportional to the width of the filament strand and inversely proportional to the twist given to the yarn and the number of filaments in the group. The ANN is much better and more accurate than regression equation with respect to prediction.
\end{abstract}

Keywords: Artificial neural network, Filament convergence angle, Spinning triangle, Number of filaments, Regression equation (RE)

\section{Introduction}

In ring frame the width of the fibre strand coming out of the front roller nip is more than the final diameter of the yarn spun. The twist flowing from the traveller shapes this strand into a triangle known as "spinning triangle". The dimensions of the spinning triangle and the distribution of fibres in it have a decisive influence on the alignment of fibres both at the surface and within the yarn. These dimensions and fibre distribution in turn are decided by the properties of the roving and the ring frame processing parameters. In the spinning triangle the front end of all the fibres are almost held with the twisted yarn portion and their back ends are held at the front roller nip. Among these fibres the edge fibres get a greater stretch, which decreases from edge to core[1]. This lead to tension differences between the fibres at spinning triangle zone thus migrates the fibre from one radial position to another radial position and the fibres are packed compactly in the yarn structure. Whereas in rotor and friction spinning systems, the fibres at yarn forming zone are not firmly held by any discrete nip point as a result of which twist runs back to the fibre strand present in the rotor groove and perforated twisting drum respectively. In both the systems, fibres are laid one over the other and on already twisted core of fibres, moreover the fibres will not get any tension differences as in the ring spinning this results in poor migration of fibres and hence yarn structure[2,3,4,5]. In case of air-jet spinning, the spinning triangle forms between front roller and first airjet nozzle. The edge fibres of the triangle are attached freely on the yarn surface and rotate around the core. In this core region migration will take place similar to that of ring spinning[5]. The second nozzle creates false twist. The twist in the yarn core is cancelled out as it comes out of the second nozzle. However the migrated fibre will not move back due to the release of twist. The air-jet yarn derives its strength from frictional cohesion of the fasciated fibres that are bound firmly around the yarn core as a result of neutralisation of the false twist. However the resulted yarn shows poor packing density compared to ring yarn. Thus the "spinning triangle" formation is essential to produce good quality yarn, which not only influences yarn tensile and surface characteristics but also the yarn's running performance and the fibre fly liberation. The untwisted fibres present at spinning triangle portion causes end breakage and the rate of breakage varies according to the size of the spinning triangle. The size of the triangle should be maintained as low as possible (i.e untwisted portion) to maximise the production rate.

The measurement of the spinning triangle dimensions for different process parameters and an understanding of its effect on yarn quality is potentially a valuable quality control tool for the textile industry. But till now the spinning triangle dimensions for staple fibres spinning could not be measured exactly while different process parameters were being changed. This was because of its small width and height. Also the whole area of spinning triangle zone is in between the front bottom and top roller and is covered due to the offset length given to the top roller. In this study, continuous polyester filaments were taken and fed at the backside of the ring frame front roller, with a particular width - which was higher than the normal existing staple fibre strand width. This resulted in a longer spinning triangle zone, forming below the front bottom roller, which enables easy measurement and also shows clear changes in spinning triangle height when the process parameters 
get changed. In recent days, artificial neural networks (ANN) have shown a great success for modelling nonlinear process. Prediction of yarn strength[6], ring and rotor yarn hairiness[7], dyeing time[8], dye concentrations in multiple dye mixtures[9], total hand evaluation of knitted fabrics[10] and tensile properties of needle punched non wovens[11], web density control in carding[12], classification of dyeing defects[13], evaluation of seem puckering in garments[14] and quality assessment of carpets[15] are some of the areas where ANNs have been attempted. In this study an attempt has been made to predict the spinning triangle height in ring frame using artificial neural networks. The results obtained from ANNs analysis are compared with those obtained from regression equation to ascertain the efficiency of the prediction of spinning triangle height by ANNs.

\section{Materials and Methods}

Continuous polyester multi-filament (34denier) yarns were taken and fed at the backside of the front roller in a ring frame through pre-tensioner and a thread guide as shown in Figure1. The thread guide enabled the feeding of the filaments at a fixed position and fixed width. The width of the filaments spread was changed from $8 \mathrm{~mm}$, to $10 \mathrm{~mm}, 13 \mathrm{~mm}, 15 \mathrm{~mm}$ and $20 \mathrm{~mm}$. The number of filaments in the group was changed from 4 to 6 , 8,10 and finally 12 . The filaments leaving from the front roller were twisted by ring-spindle and the twist inserted was changed from 15.34 TPI, to 17.74 TPI, 20.14 TPI, 22.75 TPI and 25.33 TPI. The CCD camera was fixed in front of the front roller and software was used to send a series of digital images to the computer, which was stored in hard disk. From these images, the height of the triangle at different settings was measured. All the experiments were conducted on a Lakshmi Rieter G5/1 spinning frame fitted with rings of 38-millimetre diameter. The measurements were taken when the yarn winding was taking place at full diameter of the cop bottom. Spindle speed was maintained at $8000 \mathrm{rpm}$, the offset length given to the front top roller was $4 \mathrm{~mm}$ and a Lakshmi traveller number 2 was used on the ring.

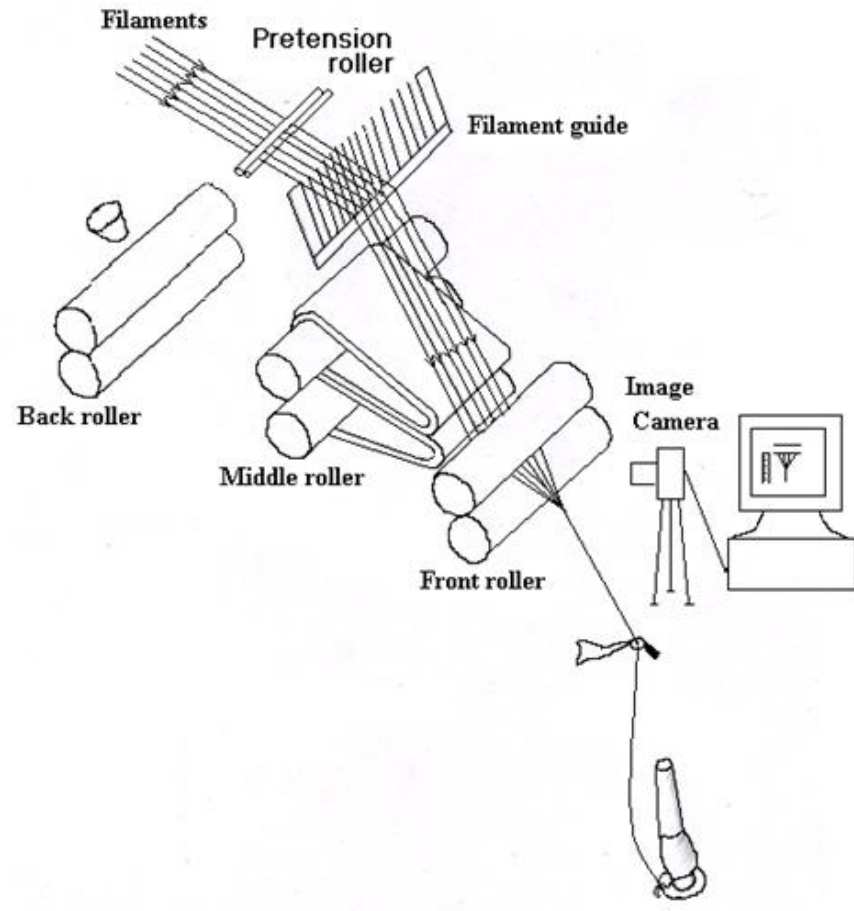

Figure 1 Method of measurement of spinning triangle height

\subsection{ARTIFiCial NEURAL NETWORK (ANN)}

The physiology of the neurons in a biological neural system - such as the human nervous system generates a very sophisticated pattern recognition capability. This has been the fundamental reason for the development of ANN based software. Software modelled on this principle can be "trained" to capture non-linear relationship between the input and the output variables. A number of different principles/models of ANN have been developed and the present most commonly used model is the layered feed forward neural network with multiple layers and with the back propagation-learning algorithm[16]. An ANN is a computing system composed of a number of highly interconnected layers of simple neurons like processing elements which process information by a dynamic response to external inputs. The information passes through the complete network with linear and non-linear transformations. The magnitude of the transformations depends on the stored 
values (weights) at each processing element. These weights are determined by "training" the neural networks that is presenting a series of cases where both the input values and the correct answers are known. Once the ANN is "trained", it can be used to predict the expected answer for new sets of input values.

In this study a multi layered feed forward neural network architecture was used (Figure 2). The circles represent the processing elements - the "neurons". As it can be seen the "neurons" are arranged in five layers. One input, one output, and three hidden layers have been used in the present study. A neuron (i) in one layer is connected with a neuron (j) in next layer with a weight of Wij. The exact values of the various Wij ‘s were determined by the data used to "train" the network. One of the most typical activation functions used in neural network training is the binary sigmoid function, which has a range of $(0,1)$. Since the binary function as a range of $(0,1)$ the values of input and output parameters have to be scale down between 0 and 1 by normalizing them with suitable factors. The ANN was trained by presenting it successively with 125 sets of input and output data sets. The input variables selected were the Twist, Number of filaments and Width of the spinning triangle. The output variable was height of the triangle. The ANN was trained up to 60,000 cycles to obtain optimum weights. The weights of ANN for height of the triangle are given in Table 1.

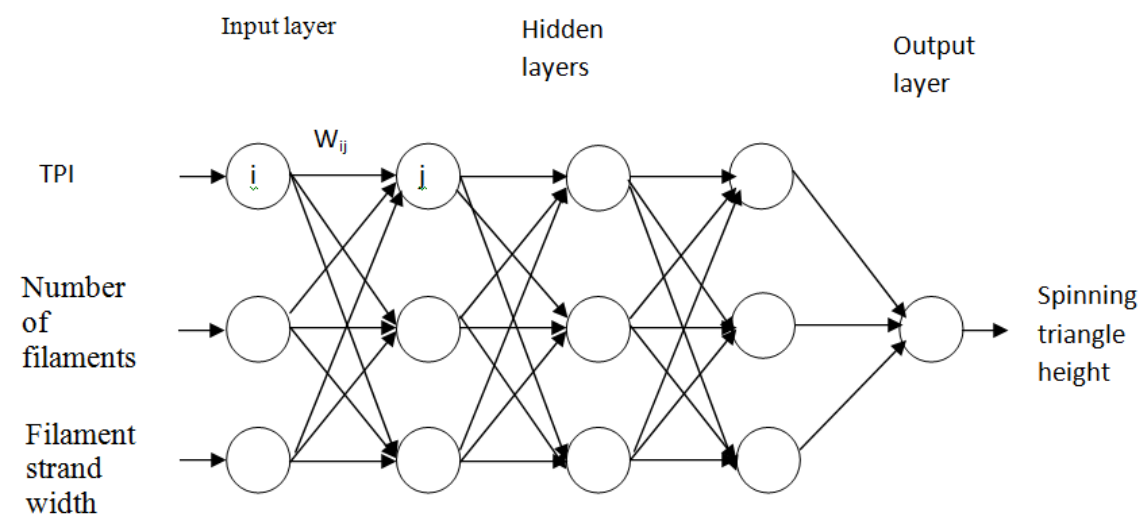

Figure 2 Artificial Neural Networks

Table 1 Weights Obtained in Training of Artificial Neural Network

\begin{tabular}{ccccc}
\hline Weights & $\mathbf{1}^{\text {st }}$ and $\mathbf{2}^{\text {nd }}$ layer & $\mathbf{2}^{\text {nd }}$ and $\mathbf{3}^{\text {rd }}$ layer & $\mathbf{3}^{\text {rd }}$ and $\mathbf{4}^{\text {th }}$ layer & $\mathbf{4}^{\text {th }}$ and $\mathbf{5}^{\text {th }}$ layer \\
\hline $\mathbf{W}_{\mathbf{1 1}}$ & 1.556876 & -11.171446 & -7.067149 & -3.375407 \\
$\mathbf{W}_{\mathbf{1 2}}$ & 3.503547 & -0.50141 & -5.675291 & \\
$\mathbf{W}_{\mathbf{1 3}}$ & -2.429895 & 0.526224 & -8.178473 & \\
$\mathbf{W}_{\mathbf{2 1}}$ & 12.531017 & 1.006557 & -1.624776 & -1.487290 \\
$\mathbf{W}_{\mathbf{2 2}}$ & 0.128461 & -1.510304 & -1.831245 & \\
$\mathbf{W}_{\mathbf{2 3}}$ & -8.206220 & -3.956986 & -0.387648 & -3.019187 \\
$\mathbf{W}_{\mathbf{3 1}}$ & -2.517908 & 10.263639 & -3.516867 & \\
$\mathbf{W}_{\mathbf{3 2}}$ & -4.348798 & 0.230849 & -3.768124 & \\
$\mathbf{W}_{\mathbf{3 3}}$ & 2.220837 & 2.599287 & -2.248510 & \\
\hline
\end{tabular}

\section{Results and discussion}

Experimentally measured spinning triangle height and the predicted values by artificial neural network and regression equation (Equation 1) are shown in Table 2.

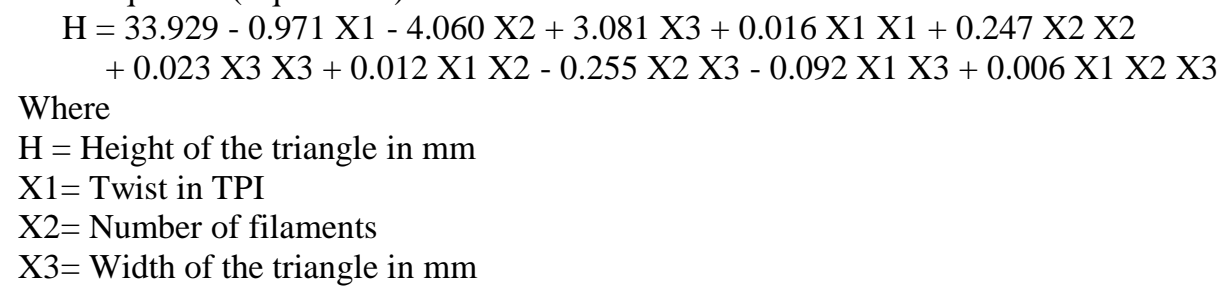

The ANN and regression equation were also presented to new sets of inputs, which have not appeared during the training phase. The corresponding spinning triangle height for those parameters was measured experimentally and predicted by ANN and regression equation. The error was calculated between the experimental and the predicted values are given in Table 3. The values predicted by ANN gives an average error of $1.02 \%$ but the values predicted by multiple regression equation gives an average error of $3.67 \%$.

\subsection{EFFECT OF FILAMENT STRAND WIDTH ON SPINNING TRIANGLE HEIGHT}


The results of the experiment given in Table 2 clearly show that the width of filament spread had a significant influence on the height of the spinning triangle. Increase in filament strand width increases the height of the spinning triangle formed below the front roller nip. Ishtiaque[17] also observed the same trend, while analysing the effect of roving strand space on siro spun yarn structure and stated that the increase in roving space increases the distance between the front roller nip and the convergence point. At an equilibrium condition, the downward force in the yarn (yarn tension) is equal to the sum of upward forces of the filaments[18]. Let us assume the $\mathrm{T}$ is tension in the yarn. T1, T2, T3...Tn are tension in the filaments and its converging angle to the yarn axis are $\Phi 1, \Phi 2, \Phi 3$ $\Phi$ n respectively, and ' $\mathrm{n}$ ' is number of filaments at spinning triangle.

$\mathrm{T}=\mathrm{T} 1 \operatorname{Cos} \Phi 1+\mathrm{T} 2 \operatorname{Cos} \Phi 2+\mathrm{T} 3 \operatorname{Cos} \Phi 3$.

.$+\mathrm{Tn} \operatorname{Cos} \Phi \mathrm{n}$

While increasing the filament strand width, the convergence angle of the filament is expected to remain the same value by increasing the height of the triangle proportionally as the other spinning parameters are kept constant, otherwise the tension either in filament or in the yarn may get change as per equilibrium condition given in equation 2 . To verify the above statement the tension was measured between lappet and front roller by using Paramount's digiTENSTM electronic yarn tension meter, the results (Table 4) of which shows that there is no significant change in yarn tension, while changing the filament strand width. But while calculating the convergence angle of the edge filament using equation 3 for the experimental and predicted values, it can be seen (Table 5) that the converging angle slightly increases while the strand width is increased.

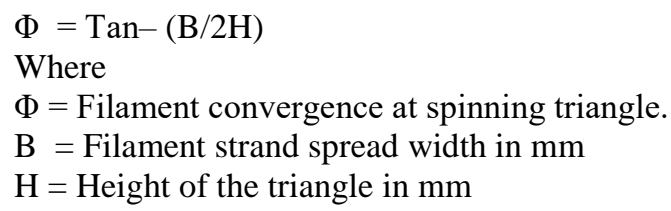

Table 2 Effect of Twist, Number of Filaments (NF) and Strand width on spinning triangle height

\begin{tabular}{|c|c|c|c|c|c|c|c|c|c|c|c|c|c|c|c|c|}
\hline \multirow{3}{*}{ NF } & \multirow{3}{*}{$\begin{array}{l}\text { Twist } \\
\text { (TPI) }\end{array}$} & \multicolumn{15}{|c|}{ Height of the triangle in $\mathrm{mm}$} \\
\hline & & \multicolumn{3}{|c|}{ Width $=8 \mathrm{~mm}$} & \multicolumn{3}{|c|}{ Width $=10 \mathrm{~mm}$} & \multicolumn{3}{|c|}{ Width $=13 \mathrm{~mm}$} & \multicolumn{3}{|c|}{ Width $=15 \mathrm{~mm}$} & \multicolumn{3}{|c|}{ Width $=20 \mathrm{~mm}$} \\
\hline & & Expt & ANN & RE & Expt & ANN & RE & Expt & ANN & $\mathbf{R E}$ & Expt & ANN & RE & Expt & ANN & RE \\
\hline \multirow{5}{*}{4} & 15.3 & 24.7 & 21.8 & 20.9 & 24.7 & 25.0 & 23.7 & 29.8 & 30.4 & 28.4 & 33.6 & 34.0 & 31.7 & 44.8 & 42.1 & 40.8 \\
\hline & 17.7 & 19.1 & 18.9 & 18.6 & 21.7 & 21.8 & 21.1 & 26.2 & 26.7 & 25.3 & 29.7 & 30.3 & 28.3 & 40.0 & 39.1 & 36.6 \\
\hline & 20.1 & 16.8 & 16.4 & 16.5 & 19.0 & 18.8 & 18.8 & 23.0 & 23.2 & 22.4 & 26.2 & 26.6 & 25.1 & 35.6 & 35.7 & 32.6 \\
\hline & 22.8 & 14.6 & 14.1 & 14.5 & 16.5 & 16.1 & 16.4 & 20.0 & 19.9 & 19.5 & 22.7 & 22.9 & 21.8 & 31.1 & 31.7 & 28.4 \\
\hline & 25.3 & 12.7 & 12.3 & 12.7 & 14.4 & 13.9 & 14.2 & 17.4 & 17.1 & 16.8 & 19.8 & 19.6 & 18.8 & 27.1 & 27.7 & 24.5 \\
\hline \multirow{5}{*}{6} & 15.3 & 15.8 & 15.7 & 15.4 & 17.7 & 17.7 & 17.7 & 21.0 & 21.1 & 21.3 & 23.5 & 23.7 & 24.0 & 30.9 & 31.0 & 31.5 \\
\hline & 17.7 & 14.1 & 14.0 & 13.5 & 15.8 & 15.7 & 15.4 & 18.7 & 18.7 & 18.7 & 20.9 & 21.0 & 21.1 & 27.7 & 27.9 & 27.9 \\
\hline & 20.1 & 12.6 & 12.4 & 11.7 & 14.0 & 13.9 & 13.4 & 16.6 & 16.5 & 16.2 & 18.6 & 18.6 & 18.4 & 24.7 & 24.9 & 24.5 \\
\hline & 22.8 & 11.1 & 11.0 & 10.0 & 12.4 & 12.3 & 11.4 & 14.7 & 14.5 & 13.8 & 16.4 & 16.3 & 15.6 & 21.8 & 21.9 & 21.0 \\
\hline & 25.3 & 9.9 & 9.9 & 8.5 & 11.0 & 10.9 & 9.6 & 13.0 & 12.8 & 11.6 & 14.5 & 14.3 & 13.1 & 19.2 & 19.2 & 17.8 \\
\hline \multirow{5}{*}{8} & 15.3 & 13.1 & 13.1 & 12.0 & 14.5 & 14.5 & 13.6 & 16.8 & 16.9 & 16.2 & 18.6 & 18.7 & 18.3 & 24.0 & 23.8 & 24.1 \\
\hline & 17.7 & 11.8 & 11.9 & 10.3 & 13.0 & 13.1 & 11.7 & 15.2 & 15.2 & 14.0 & 16.8 & 16.8 & 15.9 & 21.6 & 21.6 & 21.2 \\
\hline & 20.1 & 10.6 & 10.7 & 8.8 & 11.7 & 11.8 & 10.0 & 13.7 & 13.7 & 12.0 & 15.1 & 15.2 & 13.6 & 19.5 & 19.5 & 18.4 \\
\hline & 22.8 & 9.5 & 9.7 & 7.4 & 10.5 & 10.6 & 8.3 & 12.2 & 12.3 & 10.0 & 13.5 & 13.5 & 11.4 & 17.4 & 17.4 & 15.6 \\
\hline & 25.3 & 8.6 & 8.8 & 6.2 & 9.4 & 9.6 & 6.9 & 10.9 & 11.0 & 8.3 & 12.1 & 12.1 & 9.4 & 15.5 & 15.5 & 13.1 \\
\hline \multirow{5}{*}{10} & 15.3 & 11.8 & 11.8 & 10.5 & 12.9 & 13.0 & 11.4 & 14.8 & 14.9 & 13.1 & 16.3 & 16.3 & 14.5 & 20.5 & 20.3 & 18.7 \\
\hline & 17.7 & 10.7 & 10.8 & 9.1 & 11.7 & 11.8 & 9.9 & 13.5 & 13.5 & 11.4 & 14.8 & 14.9 & 12.6 & 18.6 & 18.6 & 16.4 \\
\hline & 20.1 & 9.7 & 9.8 & 7.9 & 10.6 & 10.7 & 8.6 & 12.2 & 12.3 & 9.8 & 13.4 & 13.5 & 10.9 & 16.9 & 17.0 & 14.3 \\
\hline & 22.8 & 8.8 & 8.9 & 6.8 & 9.6 & 9.7 & 7.3 & 11.0 & 11.1 & 8.3 & 12.1 & 12.1 & 9.2 & 15.3 & 15.3 & 12.2 \\
\hline & 25.3 & 7.9 & 8.1 & 6.0 & 8.7 & 8.8 & 6.2 & 9.9 & 10.0 & 7.0 & 10.9 & 11.0 & 7.7 & 13.7 & 13.8 & 10.3 \\
\hline \multirow{5}{*}{12} & 15.3 & 11.1 & 11.0 & 11.0 & 12.1 & 12.0 & 11.3 & 13.8 & 13.7 & 12.0 & 15.1 & 15.0 & 12.7 & 18.7 & 18.5 & 15.3 \\
\hline & 17.7 & 10.1 & 10.0 & 10.0 & 11.1 & 11.0 & 10.10 & 12.6 & 12.5 & 10.7 & 13.8 & 13.7 & 11.3 & 17.1 & 17.0 & 13.7 \\
\hline & 20.1 & 9.2 & 9.2 & 9.0 & 10.1 & 10.0 & 9.1 & 11.5 & 11.4 & 9.5 & 12.6 & 12.5 & 10.1 & 15.7 & 15.5 & 12.2 \\
\hline & 22.8 & 8.4 & 8.4 & 8.2 & 9.1 & 9.1 & 8.2 & 10.4 & 10.3 & 8.5 & 11.4 & 11.3 & 8.9 & 14.2 & 14.1 & 10.8 \\
\hline & 25.3 & 7.6 & 7.7 & 7.7 & 8.3 & 8.3 & 7.5 & 9.4 & 9.4 & 7.7 & 10.3 & 10.2 & 8.0 & 12.8 & 12.8 & 9.6 \\
\hline
\end{tabular}

$\mathrm{NF}$ - Number of filaments

ANN- Predicted values by artificial neural network,

$\mathrm{RE}$ - Predicted values by regression equation

During twisting multiple triangles were formed in the spinning triangle zone. The filaments present at the middle zone form a shorter triangle whereas the filaments at the edge zone form a longer triangle. These 
edge filaments twist over the previously formed twisted assembly at shorter triangle. Thus the movement of edge filament into the yarn structure is restricted, which leads to more tension on the filament. This phenomenon results in the upward movement of the convergence point towards the front roller nip so that the tension in the filament and yarn comes to equilibrium at the new filament convergence point.

Table 3 Experimental verification of predicted results on spinning triangle height

\begin{tabular}{|c|c|c|c|c|c|c|c|}
\hline \multirow{3}{*}{$\begin{array}{l}\text { Twist } \\
\text { (TPI) }\end{array}$} & \multirow{3}{*}{$\begin{array}{l}\text { Number } \\
\text { filaments }\end{array}$} & \multirow{3}{*}{$\begin{array}{l}\text { Width } \\
\text { Of the strand } \\
(\mathrm{mm})\end{array}$} & \multicolumn{5}{|c|}{ Spinning triangle length $(\mathrm{mm})$} \\
\hline & & & \multirow{2}{*}{$\begin{array}{l}\text { I. Experimental } \\
\text { values }\end{array}$} & \multicolumn{2}{|c|}{ Predicted values by } & \multicolumn{2}{|c|}{ Error $(\%)$} \\
\hline & & & & ANN & RE & ANN & RE \\
\hline 15.34 & 5 & 9 & 19.21 & 19.28 & 19.15 & 0.36 & 0.31 \\
\hline 15.34 & 9 & 18 & 19.84 & 19.90 & 19.03 & 0.30 & 4.08 \\
\hline 17.74 & 5 & 9 & 17.32 & 17.28 & 17.25 & 0.23 & 0.40 \\
\hline 17.74 & 9 & 18 & 18.01 & 18.37 & 16.98 & 1.99 & 5.71 \\
\hline 20.14 & 5 & 9 & 14.98 & 14.85 & 14.82 & 0.86 & 1.06 \\
\hline 20.14 & 9 & 18 & 15.99 & 16.38 & 14.32 & 2.43 & 10.44 \\
\hline \multicolumn{6}{|c|}{ Mean absolute percentage error } & 1.02 & 3.67 \\
\hline
\end{tabular}

Table 4 Effect of filament strand width, number of filaments on yarn tension

\begin{tabular}{|c|c|c|c|c|c|}
\hline \multirow{2}{*}{ Number of filaments } & \multicolumn{5}{|c|}{ Yarn tension at different spinning triangle width (g) } \\
\cline { 2 - 6 } & $\mathbf{8 m m}$ & $\mathbf{1 0 m m}$ & $\mathbf{1 3 m m}$ & $\mathbf{1 5 m m}$ & $\mathbf{2 0 m m}$ \\
\hline 4 & 25.56 & 26.34 & 24.91 & 24.32 & 27.8 \\
\hline 6 & 28.63 & 28.3 & 29.23 & 32.53 & 28 \\
\hline 8 & 31.5 & 30.83 & 31.62 & 32.58 & 30.13 \\
\hline 10 & 33.92 & 34.63 & 32.26 & 35.68 & 3 \\
\hline 12 & 35.64 & 35.52 & 36.13 & 37.23 \\
\hline
\end{tabular}

\section{EFFECT OF YARN TWIST ON SPINNING TRIANGLE HEIGHT}

From the results given in Table 2, it is observed that the increase in the yarn twist causes the convergence point to move towards the front roller nip, thereby reducing the height of the triangle and also observed that the rate of rise per twist of the convergence point gradually decreases with the increase in twist. This trend is seen at all strand widths. From the Figure 3, it can be seen that the length of the filament in contact with roller surface in the spinning triangle increases from L1 to L2 when the convergence point moves from T1 to $\mathrm{T} 2$. Increase in filament contact with the front roller surface, increases the frictional force and hence increases the resistance to rolling of the filament on the surface. This results in a decrease in the rate of twist flow.

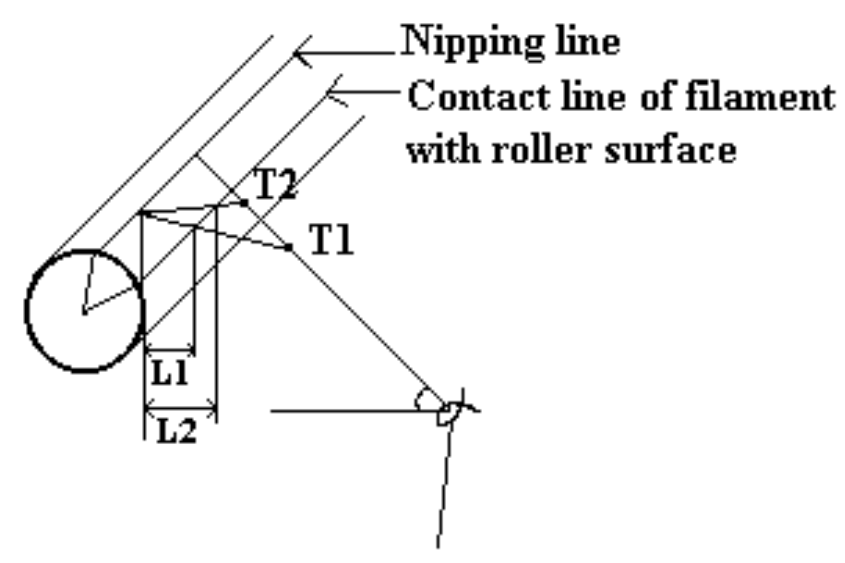

Figure 3 The length of filament over the roller surface 
Prediction of the Spinning Triangle Height in Ring Frame Using Artificial Neural Networks

Table 5 Effect of Twist, Number of Filaments (NF) and Strand width on filament convergence angle at spinning triangle

\begin{tabular}{|c|c|c|c|c|c|c|c|c|c|c|c|c|c|c|c|c|}
\hline \multirow{3}{*}{ NF } & \multirow{3}{*}{$\begin{array}{l}\text { Twist } \\
\text { (TPI) }\end{array}$} & \multicolumn{15}{|c|}{ Filament convergence angle in degree } \\
\hline & & \multicolumn{3}{|c|}{ Width $=8 \mathrm{~mm}$} & \multicolumn{3}{|c|}{ Width $=10 \mathrm{~mm}$} & \multicolumn{3}{|c|}{ Width $=13 \mathrm{~mm}$} & \multicolumn{3}{|c|}{ Width $=15 \mathrm{~mm}$} & \multicolumn{3}{|c|}{ Width $=20 \mathrm{~mm}$} \\
\hline & & Expt & ANN & $\mathrm{RE}$ & Expt & ANN & $\mathrm{RE}$ & Expt & ANN & $\mathrm{RE}$ & Expt & ANN & RE & Expt & ANN & RE \\
\hline \multirow{5}{*}{4} & 15.34 & 9.19 & 10.39 & 10.85 & 11.46 & 11.3 & 11.9 & 12.31 & 12.09 & 12.91 & 12.57 & 12.43 & 13.31 & 12.587 & 13.35 & 13.77 \\
\hline & 17.74 & 11.8 & 11.94 & 12.13 & 12.99 & 12.94 & 13.3 & 13.93 & 13.69 & 14.4 & 14.17 & 13.91 & 14.84 & 14.02 & 14.33 & 15.28 \\
\hline & 20.14 & 13.4 & 13.7 & 13.59 & 14.72 & 14.86 & 14.93 & 15.76 & 15.62 & 16.17 & 16.00 & 15.74 & 16.64 & 15.71 & 15.65 & 17.06 \\
\hline & 22.75 & 15.3 & 15.82 & 15.42 & 16.83 & 17.2 & 16.99 & 18.04 & 18.08 & 18.43 & 18.27 & 18.14 & 18.97 & 17.83 & 17.52 & 19.38 \\
\hline & 25.33 & 17.5 & 18.07 & 17.47 & 19.16 & 19.74 & 19.37 & 20.5 & 20.84 & 21.11 & 20.79 & 20.89 & 21.74 & 20.23 & 19.86 & 22.18 \\
\hline \multirow{5}{*}{6} & 15.34 & 14.2 & 14.28 & 14.52 & 15.786 & 15.8 & 15.81 & 17.23 & 17.14 & 16.95 & 17.72 & 17.58 & 17.36 & 17.91 & 17.87 & 17.62 \\
\hline & 17.74 & 15.9 & 15.98 & 16.52 & 17.61 & 17.71 & 17.95 & 19.21 & 19.2 & 19.17 & 19.74 & 19.65 & 19.57 & 19.88 & 19.73 & 19.71 \\
\hline & 20.14 & 17.7 & 17.81 & 18.86 & 19.62 & 19.76 & 20.48 & 21.37 & 21.45 & 21.79 & 21.96 & 21.95 & 22.18 & 22.06 & 21.88 & 22.17 \\
\hline & 22.75 & 19.8 & 19.91 & 21.83 & 21.97 & 22.14 & 23.73 & 23.93 & 24.09 & 25.2 & 24.59 & 24.67 & 25.59 & 24.68 & 24.53 & 25.37 \\
\hline & 25.33 & 22.1 & 22.05 & 25.19 & 24.47 & 24.58 & 27.46 & 26.65 & 26.83 & 29.2 & 27.38 & 27.54 & 29.62 & 27.51 & 27.43 & 29.18 \\
\hline \multirow{5}{*}{8} & 15.34 & 17 & 16.92 & 18.44 & 19.07 & 18.97 & 20.23 & 21.11 & 21.01 & 21.78 & 21.92 & 21.84 & 22.29 & 22.66 & 22.77 & 22.48 \\
\hline & 17.74 & 18.7 & 18.62 & 21.16 & 20.99 & 20.88 & 23.15 & 23.19 & 23.1 & 24.78 & 24.07 & 23.97 & 25.25 & 24.83 & 24.83 & 25.22 \\
\hline & 20.14 & 20.6 & 20.4 & 24.31 & 23.07 & 22.89 & 26.55 & 25.45 & 25.31 & 28.28 & 26.4 & 26.25 & 28.71 & 27.17 & 27.09 & 28.37 \\
\hline & 22.75 & 22.8 & 22.41 & 28.21 & 25.46 & 25.16 & 30.78 & 28.07 & 27.84 & 32.68 & 29.07 & 28.88 & 33.06 & 29.92 & 29.74 & 32.36 \\
\hline & 25.33 & 25.1 & 24.46 & 32.41 & 27.98 & 27.48 & 35.44 & 30.79 & 30.4 & 37.53 & 31.88 & 31.55 & 37.9 & 32.78 & 32.5 & 36.88 \\
\hline \multirow{5}{*}{10} & 15.34 & 18.8 & 18.68 & 20.77 & 21.19 & 21.05 & 23.56 & 23.67 & 23.52 & 26.24 & 24.73 & 24.61 & 27.23 & 26.01 & 26.1 & 27.97 \\
\hline & 17.74 & 20.6 & 20.37 & 23.59 & 23.14 & 22.96 & 26.7 & 25.76 & 25.59 & 29.6 & 26.91 & 26.7 & 30.6 & 28.21 & 28.14 & 31.12 \\
\hline & 20.14 & 22.4 & 22.15 & 26.65 & 25.19 & 24.94 & 30.17 & 28.01 & 27.76 & 33.29 & 29.2 & 28.95 & 34.31 & 30.55 & 30.35 & 34.58 \\
\hline & 22.75 & 24.6 & 24.12 & 30.15 & 27.56 & 27.17 & 34.18 & 30.58 & 30.22 & 37.59 & 31.86 & 31.49 & 38.64 & 33.25 & 32.89 & 38.67 \\
\hline & 25.33 & 26.8 & 26.09 & 33.52 & 30.00 & 29.37 & 38.09 & 33.21 & 32.65 & 41.86 & 34.56 & 34.03 & 42.94 & 36.05 & 35.51 & 42.82 \\
\hline \multirow{5}{*}{12} & 15.34 & 19.8 & 20.00 & 19.9 & 22.44 & 22.58 & 23.84 & 25.19 & 25.3 & 28.28 & 26.43 & 26.51 & 30.31 & 28.11 & 28.28 & 32.89 \\
\hline & 17.74 & 21.6 & 21.71 & 21.89 & 24.35 & 24.48 & 26.25 & 27.27 & 27.37 & 31.12 & 28.58 & 28.62 & 33.28 & 30.28 & 30.33 & 35.77 \\
\hline & 20.14 & 23.4 & 23.47 & 23.86 & 26.36 & 26.45 & 28.68 & 29.46 & 29.54 & 33.97 & 30.82 & 30.85 & 36.26 & 32.58 & 32.52 & 38.73 \\
\hline & 22.75 & 25.5 & 25.42 & 25.82 & 28.71 & 28.65 & 31.17 & 31.96 & 31.94 & 36.95 & 33.41 & 33.32 & 39.38 & 35.21 & 35.02 & 41.84 \\
\hline & 25.33 & 27.7 & 27.35 & 27.41 & 31.10 & 30.81 & 33.29 & 34.55 & 34.32 & 39.55 & 36.03 & 35.78 & 42.12 & 37.91 & 37.54 & 44.66 \\
\hline
\end{tabular}

$\mathrm{NF}$ - Number of filaments,

ANN- Predicted values by artificial neural network,

RE - Predicted values by regression equation

\section{EFFECT OF NUMBER OF FILAMENT ON SPINNING TRIANGLE HEIGHT}

The results of spinning triangle height while increasing the number of filaments are shown in Table 2. From these results we can see that the increase in the number of filaments reduces the spinning triangle height. The increase in the number of filaments usually increases the diameter of the yarn therefore during twisting the filament at yarn surface will take a greater helical path length and helix angle. This results in a higher twist flow rate and a smaller triangle height for the same TPI and strand width. The rate of twist flow initially high and then decreases gradually while increasing the number of filaments. This is due to number of filaments required in each successive layer of the yarn structure. Hearle1 has derived equation to measure the number of fibres present in the layers of the yarn for different types of fibre packing. At the centre of an open packed assembly of circular fibres starts with a single fibre, around this six fibres should be packed to form the second layer, while twelve fibres must be available for a complete third layer. Thus an increase in the number of filaments will initially result in a rapid increase in the diameter of the yarn, but it will require an even a greater number of filaments to keep increasing the diameter of the yarn by proportionate amounts.

\section{Conclusion}

The spinning triangle height in ring frame can be predicted from regression equation and ANN. Based on the above study, it may be concluded that ANN may be used successfully for predicting spinning triangle height. The ANN model has been found to be more accurate that the regression equation. The regression equation developed has a coefficient of determination (R-Square) of 0.985 . The ANN developed has a coefficient of determination (R-Square) of 0.998 . The increase in filament strand width increases the height of spinning triangle and increases slightly the filament convergence angle. Increase in twist reduces the spinning triangle height at the same time the rate of convergence point movement towards front roller nip gradually decreases.Increase in number of filaments in the feed group reduces the spinning triangle height at the same time the rate of decrease in spinning triangle height gradually decreases.

\section{References}

[1] Hearle JWS, Grosberk P and Backer S, The Structural mechanics of fibres, yarns and fabrics, Wiley-interscience, Newyork, 1969.

[2] Alagha MJ, Oxenham W and Iype C, Text Res J, 1994; 64:185.

[3] Hearle JWS, Lord PR and Senturk N, J Text Inst, 1972; 63:605.

[4] Lord PR, Textile Res. J, 1971; 41:778.

[5] Peter RL, Handbook of Yarn Production Technology, Science and Economics, Wood Head Publishing Ltd, Cambridge England, 2003. Luo C and Adams DL, Text Res J, 1995; 65: 495. Reiyao Z and Dean EM, Text Res J, 67(1997) 694. 
[6] Senthilkumar M and Selvakumar N, Achieving expected depth of shade in reactive dye application using artificial neural network technique, Dyes and Pigm. 2005; 68: 89-94.

[7] Jasper WJ, Kovacs ET and Berkstresser WGA, Text Res J, 1993; 63:545.

[8] Shin WP, Young-gu H, Bok-ehoon K and Seong-won Y, Text Res J, 2000; 70: 675.

[9] Debnath S, Madhusoothanan M and Srinivasmoorthy VR, Indian J Fibre Text Res, 2000; $25: 31$.

[10] Chung-ferg JK, Charg-chung W and Chien-terg H, Text Res J, 1999; 69: 401.

[11] Chang-Chiun H and Wen-Hong Y, Text Res J, 2001; 71: 100.

[12] Chang KP and Tal JK, Text Res J, 1997; 67: 494.

[13] Sette S, Boullart L and Keikens P, Text Res J, 1995; 65:196

[14] Rao V and Rao H, C++ neural networks and fuzzy logic, BPB publications, New Delhi, India, $1996 ; 337$.

[15] Ishtiaque SM, Dhawan K, Saxena A, and Prakash J, Structural mechanics of double roving feed yarn - A longitudinal view, BTRA, 29th technological conference,1988; March: 35

[16] Fraser WB, \& Stump DM, Int J Solids Structures, 1998; 35: 285. 